\title{
Using Singing and Movement to Teach Pre-reading Skills and Word Reading to Kindergarten Children: An Exploratory Study
}

\author{
PATRICK D. WALTON \\ Thompson Rivers University
}

\begin{abstract}
Kindergarten classrooms were randomly assigned to a songs group $(n=44)$ that used choral singing and movement to teach phonological skills, letter-sounds, and word reading, or to a control group $(n=49)$ where children received their regular language and literacy programs for equal amounts of time. The songs group teaching involved choral singing and movements created for the project to teach phonological skills, letter-sounds, and word reading. Children preferred songs that were quick to learn, had strong or soothing rhythms, and incorporated movements. Children in the songs group had increased letter-sounds, medial phoneme identity and word reading compared to children in the control group. Children in both groups made equal gains in rhyming and identifying phonemes in initial and final positions. Songs group children also read new words not presented in the songs program. Initial and medial phoneme identity and lettersound knowledge made independent contributions to word reading.
\end{abstract}

Research on reading acquisition over the last 15 years has found a consistent and robust relationship between children's ability in phonological awareness and their progress in learning to read (for reviews see Ehri, Nunes, Stahl, \& Willows, 2001; Kamil, Pearson, Moje, \& Afflerbach, 2011). Although there were frequent recommendations over the previous two decades to use songs to teach phonological awareness and reading (e.g., Adams, 1990; Cooper, 2010; Kolb, 1996; Paquette, \& Rieg, 2008) - in particular rhyming and phoneme skills - there is little empirical research that examined the effects of using children's songs to teach these abilities. Recent research found connections between music and language that includes the transfer of abilities between music and speech (Besson, Chobert, \& Marie, 2011) and so supported the use of songs to teach key pre-reading skills. In addition, musical meter was found to predict phonology and reading (Goswami, Huss, Mead, Fosker \& Verney, in press; Huss, Verney, Fosker, Mead, \& Goswami, 2011), and Patel (2011) summarized brain research that could explain why experience with music could account for increased abilities with speech. This recent research provides a strong rationale for examining the effects of using songs to teach key pre-reading and word reading skills. The research presented here is a study designed to examine the effects of such a program in a school setting.

A song is basically words put to rhythm. Learning to sing a song is quite easy for children if the ending words rhyme, if there is a strong rhythm or beat, and if there are 
few words to remember. In previous research, children appeared to learn new words more easily and remember the words longer when jingles were used to teach the reading of words that rhymed (Walton, Bowden, Kurtz, \& Angus, 2002; Walton, Walton, \& Felton, 2001; Walton, \& Walton, 2002). For example, showing pre-readers the printed words rat and sat and having them sing the words as a jingle (rat sat, rat rat sat) was an effective method to teach phonological skills and word reading and was an experience that the children appeared to enjoy.

There are several reasons why the jingles, which are brief songs, are effective in teaching reading, and three possible explanations are considered here. First, having children sing songs while viewing printed words may strengthen the phonological and text connections in long-term memory, and so act as a memory aid when children were asked later to read the words. Also, Walton et al. (2002) noted that children often sang the jingles without prompting immediately following the first teaching sessions, and so it took very few presentations for the children to learn and remember the jingles.

Songs that segment words or include rhyming words can manipulate words at the phonemic and onset-rime level and so potentially can teach these phonological awareness skills. Phonological awareness, typically defined as conscious access to sounds within words and the ability to manipulate these sounds, is consistently the pre-reading ability most strongly related to success in reading. The strong link between early knowledge of nursery rhymes and the development of phonological skills and emergent reading is evidence that hearing language spoken with rhythm teaches these important reading skills (Maclean, Bryant, \& Bradley, 1987). To go from hearing and saying nursery rhymes to singing songs is a small step. Learning to sing songs with lyrics that rhyme might also teach important pre-reading skills and word. However, surprisingly little research has examined the connection between music and language and so the specific mechanisms that could account for the connection are unclear.

\section{Literature Review}

There is a commonly held view that there is strong research linking music and song to developmental gains and reading acquisition, but few studies have experimentally examined these claims. The literature on this link has produced mixed results. The popular "Mozart Effect" stimulated much of this research. In 1993, Rauscher, Shaw, and Ky published a report titled Music and spatial task performance in nature. College students who listened to Mozart sonatas increased their performance on a subsequent spatial intelligence test by eight to nine IQ points in comparison to control conditions where they either listened to relaxation instructions or sat in silence for identical periods of time. This finding became known as the "Mozart Effect." Several researchers began to examine the Mozart Effect and, in 1999, a meta-analysis of 16 studies came to the conclusion that the overall effect size was negligible (Chabris, 1999). At least partially driven by the initial research by Rauscher et al. (1993), other researchers began to examine potential links between music and other subject areas, including reading.

Three meta-analyses and a literature review on the links between music and reading found variable results. Butzlaff (2000) presented separate meta-analyses on correlational 
studies and experimental studies and found that most music education students had higher scores on standardized reading tests than non-education students. However, experimental studies found variable effects for music programs on reading achievement. Music programs that targeted reading or phonological skills specifically had stronger effects on reading than more general music programs (e.g., Register, 2001; Standley, \& Hughes, 1997; Tendall, 2009). Standley (2008) found that a variety of music interventions were related to reading achievement and had effect sizes that resulted in moderately strong effects with an overall effect size of $d=0.32$. Like Butzlaff, Standley found that music activities that incorporated specific reading skills had stronger effects compared to activities that did not. Also, all schedules of intervention were equally effective regardless of whether they were daily, intense, short-term, or weekly interventions spread across the school year. Bolduc (2008) in his literature review concluded that many researchers found that musical activities promote the development of auditory perception, phonological memory, and metacognitive knowledge. Tendall (2009) found that children in an extracurricular music class scored the same on tests of reading skills as those who played non-musical reading games. However, the musical activities in the music group were not designed to teach specific reading skills.

In addition to the meta-analyses, a number of authors recommended the use of songs and music to enhance the teaching of pre-reading and reading skills (Cooper, 2010; Fisher, \& McDonald, 2003; Hansen, Bernstorf \& Stuber, 2004; Hill-Clarke \& Robinson, 2004; Moyeda, Gomez, \& Flores, 2006; Routier, 2003). Three recent correlational studies found significant relationships between music aptitude or perception and phonological awareness and reading (Anvari, Trainor, Laurel, Woodside, \& Levy, 2002; Peynircioglu, Durgunoglu, \& Oney-Kusefoglu, 2002; Rubinson, 2010). Anvari et al. examined relationships among phonological awareness, music perception skills, and early reading skills in 100 preschoolers. They found that music skills correlated significantly with both phonological awareness and reading development, and that music skills contributed unique variance in predicting reading ability, even when the effects of phonological awareness and other cognitive abilities (mathematics, digit span, and vocabulary) were accounted for. Earlier research by Lamb and Gregory (1993) concluded that the specific awareness of pitch changes was related to phonemic and musical sound discrimination.

Recent experimental research has examined the effects of music programs on phonological and other pre-reading skills and reading, with variable effects. Music programs that included the specific teaching of phonological skills (Bolduc, 2009; Bowen, 2010; Gromko, 2005; Herrera, Lorenzo, Defior, Fernandez-Smith, \& CostaGiomi, 2011; Overy, 2003) found significant effects on pre-reading skills and naming speed. However, these studies did not examine the effects of the music programs on reading with the exception of Overy. Overy found that the group lessons she provided to children with reading dyslexia that were based on singing and rhythm games increased phonological and spelling skills, but not reading. This finding was surprising given the positive effects on phonological skills and spelling. Perhaps a longer intervention period might have resulted in increases in reading as well. These findings, and the other related research reviewed previously, point the way to a line of inquiry to see if songs, which are 
essentially words put to music, enhance the learning of phonological awareness, lettersound knowledge, and word reading.

Although there is evidence that jingles and songs are effective in teaching key prereading skills to young readers (e.g., Walton et al., 2010), the cognitive mechanisms that could explain this result are unclear. New lines of research examining prosody, musical beat, and reading may, in the future, provide an explanation of the potential link between singing, movement, and word reading (Besson, Chobert, \& Marie, 2011; Goswami, 2012; Goswami, Huss, Mead, Forsker, \& Verney, in press). Prosody is the rhythm, stress, and intonation of speech, including pitch, which rises and falls within words and syllables as we speak. A potentially important marker is the rise of pitch within and between syllables (e.g., Goswami, 2012).

In summary, there is sufficient and compelling research to support the view that singing could be used effectively to teach phonological skills and reading to young children. However, there is a shortage of experimental literature on this topic. The research reported here used a controlled experiment to determine if singing and movement could be used effectively to teach phoneme awareness, rhyming, letter-sound skills, and word reading to pre-reading Kindergarten children. To increase the ecological validity of the study, the project was carried out in a school setting with 93 Kindergarten children across six classrooms.

The research presented here seeks to fill an important gap in the literature on the potential effects of using songs and movement to teach important pre-reading skills and reading 3-letter words. The present study (a) sampled Kindergarten children, (b) measured the pre-reading skills of rhyming, phoneme identity, and letter-sound knowledge, (c) tested for reading for words used in the teaching and new words not presented previously, and (d) included a control group to estimate the effects of literacy instruction in the control group classrooms. The following research questions were examined in the study:

(a) Will experience with singing and movement increase phoneme identity, rhyming, and letter-sound knowledge compared to a control group?

(b) Will experience with singing and movement increase word reading compared to a control group?

(c) Will children be able to generalize their reading to include words not presented in the songs and movement program?

(d) Will phoneme identity, rhyming, and letter-sound knowledge make independent contributions to word reading?

\section{Method}

Children in the control group received their regular classroom language and literacy teaching, and children in the treatment group received the songs program as part of their literacy teaching. The teachers in the songs group were asked not to increase the total teaching time for children so that both treatment and control groups received equal time on classroom language and literacy experiences. Thus, any increases in pre-reading skills 
and word reading in the songs group over the control group at the post-test could not be attributed to more time spent on literacy experiences in the songs classrooms.

The school district identified literacy in the primary grades as an important goal and the participating teachers received training in early reading and phonological awareness over the previous two years from school district staff, but not from the author. At meetings with the participating teachers after completion of the project, all control group teachers indicated that they sang songs with their Kindergarten students, but not regularly, and not with the intention of teaching specific pre-reading skills or reading.

Treatment group teaching took place twice a week for 12 weeks, with each session lasting about 20 minutes. Several of the teaching sessions with the songs program were videotaped for review and more detailed analysis.

\section{Participants}

Children were solicited from six different Kindergarten classrooms in four different schools across two consecutive years. The study began with 101 children, but four children moved away during the study. Also, four children read all of the words in the reading pre-test. These strong readers were not included in this report. Complete data was available for the final sample of 93 children. The average age of the 93 children (46 girls and 47 boys) in the study was five years, six months $(S D=3.44)$. The schools were located in varying socio-economic areas of a medium-sized city in the interior of British Columbia, Canada.

The research project was carried out in elementary schools and assigning children to groups within classrooms would have been too disruptive. However, the six classrooms were randomly assigned to the songs or control groups and there were no significant differences between the groups on any of the pre-reading skills and reading pre-test scores $($ all $p \mathrm{~s}>.05)$.

Tests

Children were pre-tested and post-tested (12-week interval) for rhyming ability, phoneme identity, letter-sound knowledge, and word reading.

Rhyming. Rhyming was measured with a rhyme generation task where children were given two examples of rhyming words (cat rat hat, red bed fed) and then given 30 seconds to generate words that rhyme with day and bell. The number of rhyming words generated were summed for a total rhyming score.

Phoneme Identity. The Yopp (1988) Sound Isolation Test was used to measure phoneme identity. The test measured the ability to identify phonemes in the initial, final, and then medial positions. This test had the highest predictive correlation with a subsequent measure of learning to read novel words $(r=.72)$ with Kindergarteners (Yopp, 1988). The test consisted of one practice trial with corrective feedback and then 15 experimental trials, also with corrective feedback. In each trial, the child listened to a spoken word and was then asked to identify the initial, final, or medial sound, with five 
words for each phoneme position. The scores were summed to produce a total score for phoneme identity (maximum score $=15)$.

Letter-sound Knowledge. Children were presented with two $21 \mathrm{~cm} \times 28 \mathrm{~cm}$ cards that listed the letters of the alphabet in alphabetical order in a $2 \mathrm{~cm}$ Century Gothic font in lowercase. One card listed the letters from $a$ to $o$ and the second card listed the remaining letters. Children were asked to provide the sound of individual letters and those who responded with the name of the letter were asked to say the sound of the letter. The total letter-sound score was the number of letter-sounds the children identified correctly.

Word Reading. The reading test consisted of 12 words presented on a list in 16 point Century Gothic font with all words presented individually without clues or other contextual information (see Appendix A for a list of the words). All reading test words had three letters and followed a consonant-vowel-consonant format. The first eight words were presented in the song and movement program and the remaining four words were not used in the songs program. Children were post-tested for the eight words that were presented in the song program to determine if the program was effective in teaching these words. There is little empirical research on the use of songs to teach reading and testing for this would provide a direct test of that hypothesis.

To preclude the explanation that gains in reading the program words were due to children sight-reading the first eight words by memory, four words not used in the program were added to the reading test. Testing for reading the last four words examined if the children were able to generalize their reading skill to new words and, if successful, provide evidence that the children also read the first eight words.

\section{Children's Song Preferences and Movement}

The 18 original songs created for the project were written, piloted and recorded by three musicians, one of whom was the researcher. To empirically study the idea that songs and movement could be used to teach pre-reading skills and reading effectively, we needed songs that contained words that were appropriate for young children learning to read. Existing children's songs were considered for the project and all were rejected as unsuitable, primarily because the songs used multi-syllable words which were too complex for beginning readers. In the end, we recorded 12 original children's songs designed to teach rhyming, phoneme skills, letter sound, and reading simple three-letter consonant-vowel-consonant words.

We found that the Kindergarten children preferred songs that were brief (less than 90 seconds), easy to learn (after two repetitions they could begin to sing along), and had a pronounced rhythmic beat or were slower and relaxing like lullabies. We also noticed that all of the children moved their bodies to the beat of the songs, and we piloted a variety of movements to accompany the songs (see Appendices B and C for examples of songs and activities). The movements varied by child and across different songs and included hand, leg, and full-body dancing, all unsolicited. We became interested in finding out if children preferred songs with movements, and, if they did, what types of movement did 
they prefer? To examine this question, we wrote songs that incorporated different types of movement, especially hand and arm movements, including American Sign Language. We played the new songs for the children live with and without the body movements. Then we asked children to say which song they liked better, and, every time, children preferred songs with movement compared to songs without movement.

The preferred teaching sequence, which we determined through the pilot study, was to teach the songs and accompanying body movements and then present children with the text of the lyrics while singing the songs. During the pilot, we concurrently played the songs, demonstrated the movements, and showed the printed text on large cards in 170 point Century Gothic font. If the children liked the song they responded quickly and consistently by copying the body movements first, singing along with the song, and, finally, some attended to the printed text. If children did not like a particular song, they typically stopped paying attention within the first 30 seconds and appeared bored. The differing children's responses to the songs were used to select the songs for the project.

\section{Teaching in the Songs Group}

We created 18 songs and piloted the songs with Kindergarten children, and dropped six of the songs as a result of the pilot. The choral singing aspect of the songs program provided scaffolding for the children who were slower to learn the songs and movements as the more capable children surrounded their peers with effective models. We observed the weaker children initially singing the few lyrics they knew while the rest of the group carried the song. The success of the scaffolding aspect of the choral singing for the weaker children was an unanticipated and potentially important finding.

All teaching took place in the Kindergarten classroom with all children sitting on the carpet facing the research assistant. Two research assistants, one per classroom, implemented the song and movement activities. The classroom teacher observed the activities, but did not participate in or teach the activities. So, any differences between the songs and control group were not due to having a second person in the classroom. The teaching sessions typically began with a brief period (i.e., about 30 seconds) of children singing the songs as a choral group, along with the CD that contained the songs prepared for the project. Children copied the research assistant doing the movements that were demonstrated, and sounded out selected lyrics from the song (e.g., bug b-u-g, bit b-i-t). See Appendices B and C for more complete examples of the songs. There were 12 songs in total, all original songs created and recorded for the study, so that we could control the stimulus items used in the teaching. All of the songs, except for two, had movements to accompany the singing. The movements were different for each song and included sign language and small and large motor movements.

Appendices $\mathrm{B}$ and $\mathrm{C}$ provide examples of the songs used in the treatment condition. Appendix B presents a song called Bumblebee Bill. Children first listened to the recorded song and then learned the songs and accompanying actions while singing along to the song as a group. After children had learned the songs, text with the printed words bug $b$ $u-g$, bit $b-i-t$ were shown to the children as a group as they sang the chorus. Later, children practised singing the song without the recording while looking at the presented 
text. Appendix C presents a song called I Am A Bug. After children learned the songs, children were shown text with rhyming words that emphasized common rimes (e.g., bug rug, fat cat). The songs and activities in the treatment group taught letter-sounds, phoneme identity, segmentation, and blending at the phoneme level (e.g., c-a-t cat), and used rhyming words to emphasize the onset-rime level (bug rug, fat cat). As well, all of the songs contained words that rhymed and attention was focused on these rhyming words as they sang the songs, a process that was intended to teach rhyming.

It was apparent by the children's response in the song treatment group that they enjoyed the choral singing and movements used in the teaching activities. The participating teachers commented that the children looked forward to the activities and would often be heard singing the songs at recess and other times of the day. Parents also reported that the children sang the songs at home and acted out the accompanying movements.

\section{Limitations}

It was not possible to randomly assign children to treatment groups within classrooms rather than assigning whole classrooms to the groups because having children leave the classrooms to receive the songs program would have been too disruptive to the classrooms involved. The pre-tests were administered five months into the school year and, as there were no significant differences between the songs and control groups at the time of the pre-test, this provided evidence that the classroom language and literacy programs were equally effective prior to the start of the project.

We periodically videotaped the songs classrooms to confirm treatment fidelity and study the development of the pre-reading skills and word reading over time; we did not observe the literacy and language teaching in the control group to examine other differences in their programs. The project was carried out in different schools over two years and it is possible that the control group teachers learned about the songs program. Although there was no evidence that this occurred, any treatment contamination would work against the songs group having increased scores over the control group.

The project was carried out with Kindergarten children in six different elementary schools and as a result, the study has strong ecological validity. This increases the generalizability of the findings to similar school settings. However, elementary classrooms are highly interactive environments and it is not possible to exercise the control associated with more clinical trials. For example, even though teachers in the three songs classrooms were asked not to increase the time spent on literacy, it was not possible to control for this. Although unlikely, it is possible that the lower scores on prereading skills and reading for the control group were due to decreased classroom time spent on literacy in those classrooms.

\section{Results}

The quasi-experimental design used in the study allowed for an examination of the effects of the songs program on important pre-reading skills and word reading. The results are presented starting with (a) an examination of the correlations among the pre-reading 
and reading skills, (b) tests of the effects of the songs teaching compared to the control group, and (c) an examination of the independent contribution of the pre-reading skills to word reading.

The correlations among the post-test scores and total word reading are shown in Table 1. All of the pre-test scores were normally distributed (all skewness and kurtosis $<1.68$ ). It is notable that all of the phonological and letter-sound pre-reading skills were significantly correlated with each other, and that the relationship between each pre-reading skill and reading was significant.

Table 1

Correlations Among Post-test Pre-reading Skills and Reading $(N=93)$

\begin{tabular}{|c|c|c|c|c|c|c|}
\hline Post-test measure & 2 & 3 & 4 & 5 & 6 & 7 \\
\hline 1. Rhyming & $.36^{* *}$ & $.22^{*}$ & $.40^{* *}$ & $.46^{* *}$ & $.44^{* *}$ & $.36^{* *}$ \\
\hline 2. Letter-sounds & -- & $.53^{* *}$ & $.62^{* *}$ & $.66^{* *}$ & $.72^{* *}$ & $.67^{* *}$ \\
\hline 3. Initial phoneme identity & & -- & $.42^{* *}$ & $.50^{* *}$ & $.72^{* *}$ & $.43^{* *}$ \\
\hline 4. Medial phoneme identity & & & -- & $.73^{* *}$ & $.88^{* *}$ & $.79^{* *}$ \\
\hline 5. Final phoneme identity & & & & -- & $.90^{* *}$ & $.62^{* *}$ \\
\hline 6. Total phoneme identity & & & & & -- & $.75^{* *}$ \\
\hline 7. Reading total & & & & & & -- \\
\hline
\end{tabular}

Treatment Effects on Pre-reading Skills

Treatment effects on the three pre-reading skills of letter-sounds, phoneme identity, and rhyming, were analyzed using a separate analysis of covariance (ANCONVA) for each measure. The pre-test score served as the covariate, the post-test score as the outcome variable, and treatment condition (Songs, Control) as the betweensubject factor. The analyses were based on the adjusted mean scores. A Bonferroni family-wise error correction ( $p$ divided by 5 ) was used to control for type I error which set the significant level set at $p<.01$ for each test. The analyses of the pre-reading skill results are presented in Table 2.

Table 2 shows that there was a significant ANCOVA for letter-sounds, but not for rhyming and initial, medial, and final phoneme identity. Note that children in the control group, who all received literacy experiences in their classrooms made gains in rhyming and initial, medial, and phoneme identity that were comparable to the gains made by 
children in the treatment group. Table 2 shows that although medial phoneme identity was significant at the $p<.05$ level, the Bonferroni correction to control for a false positive increased the statistically significant level to $p<.01$. The findings on the prereading skills were evidence that letter-sound skills are more effectively taught using songs and movement compared to the typical classroom literacy activities experienced by the Kindergarten children in the study.

Table 2

Treatment Effects on Pre-reading Skills

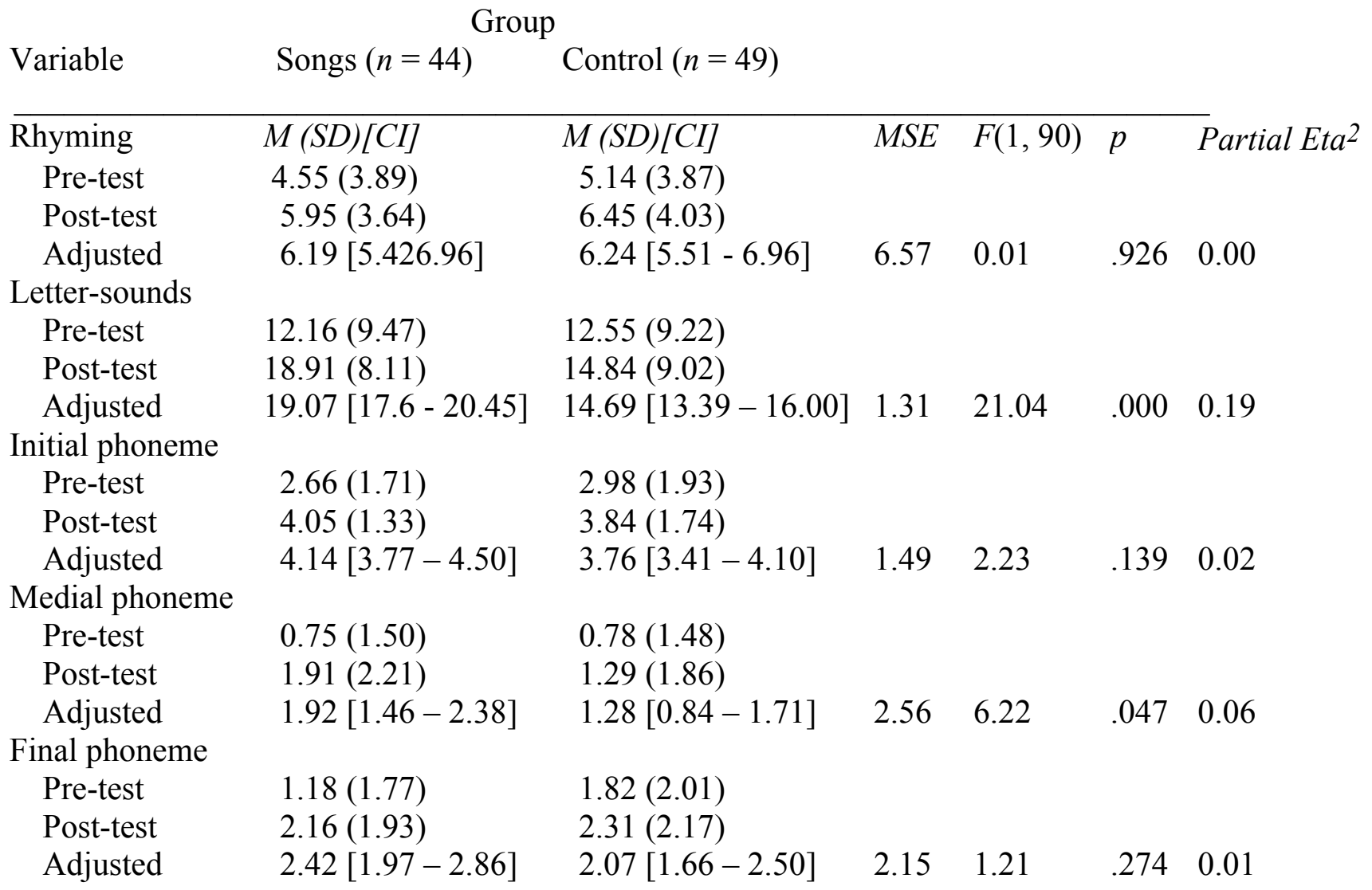

Note. $M=$ mean, $S D=$ standard deviation, $C I=95 \%$ confidence intervals. 
Figure 1 shows that using songs and movement facilitated the development of letter-sound skills compared to regular classroom literacy activities. There was a ceiling effect for letter-sounds with children in the songs treatment group (15 of the 47 children knew all 26 letter-sounds compared to eight of 49 in the control group) and so the observations reported here may underestimate of the positive effects of teaching lettersounds using songs and movements.

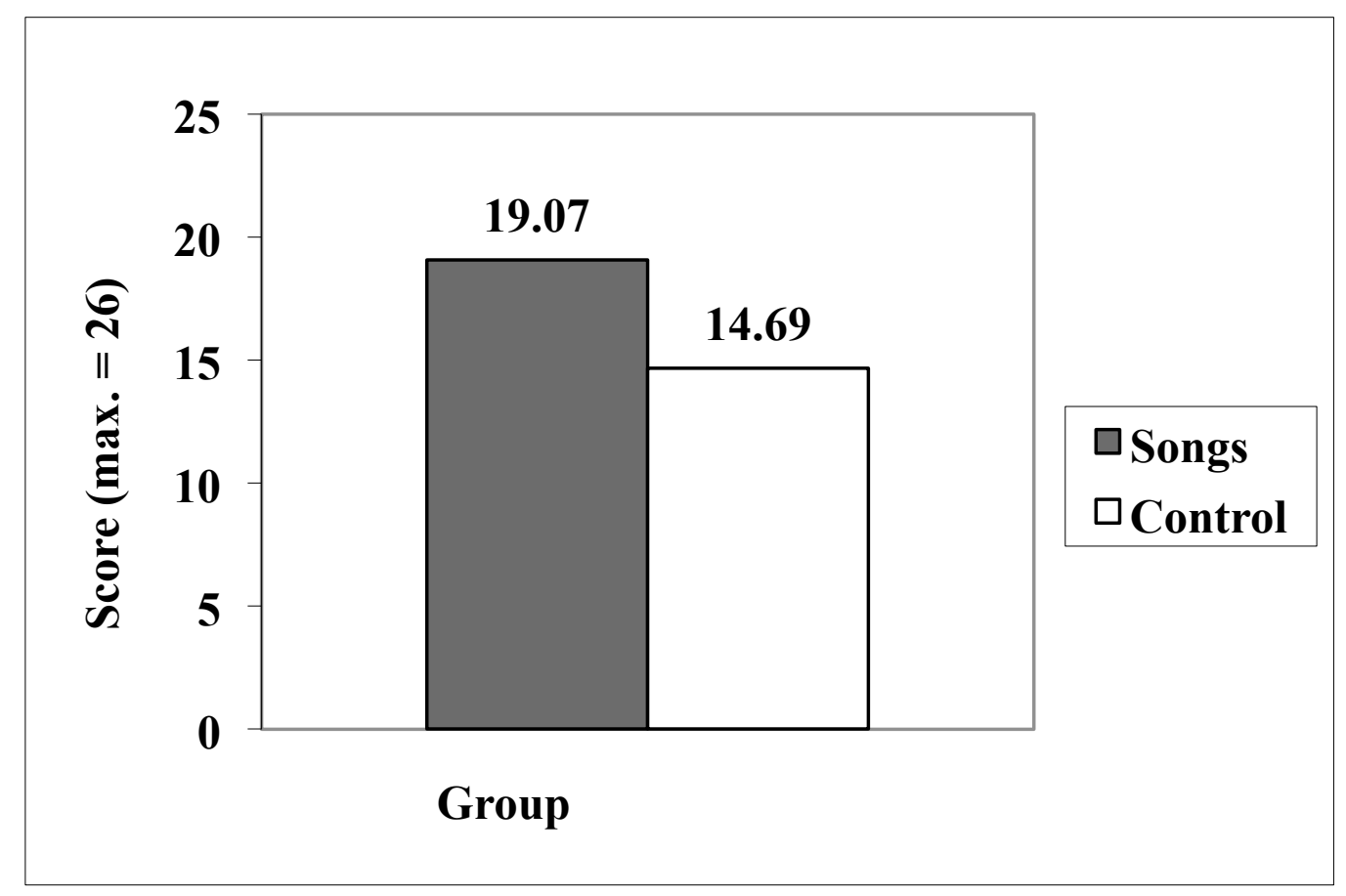

Figure 1. Treatment Effects on Letter-sounds

\section{Treatment Effects on Word Reading}

The reading assessments consisted of 12 words. The first eight words had been presented to the children in the treatment condition as lyrics in the songs and so they had previous experience with these words. Still, the reading test words were presented in a list without context and they appeared to be sounding out the words letter-by-letter rather than using a sight word based memory process. The last four words on the reading test 
were not used in the songs treatment condition and were included in the reading assessment to test children's ability to transfer their reading skill to unfamiliar words (see appendix A). Treatment effects on reading were examined using a separate ANCOVA for each reading assessment and for the total reading score, which summed the two reading assessments (maximum $=12$ ). The pre-test score served as the covariate, the post-test score as the dependent variable, and treatment condition (songs, control) as the betweensubject variable. The analyses were based on the adjusted mean scores. The results of the statistical analyses are presented in Table 3 below.

Table 3

Treatment Effects on Reading

\begin{tabular}{|c|c|c|c|c|c|c|}
\hline Variable & $\begin{array}{r}\text { Group } \\
\text { Songs }(n=44)\end{array}$ & Control $(n=49)$ & & & & \\
\hline Treatment words & $M(S D)[C I)$ & $M(S D)[C I]$ & $M S E$ & $F(1,90)$ & $p$ & Partial Eta ${ }^{2}$ \\
\hline Pre-test & $1.11(1.97)$ & $1.00(1.96)$ & & & & \\
\hline Post-test & $4.00(2.97)$ & $1.33(2.21)$ & & & & \\
\hline Adjusted & $3.95[3.32-4.59]$ & $1.37[0.76-1.97]$ & .55 & 4.03 & .000 & 0.27 \\
\hline \multicolumn{7}{|l|}{ New words } \\
\hline Pre-test & $0.50(1.09)$ & $0.49(1.10)$ & & & & \\
\hline Post-test & $1.30(1.57)$ & $0.67(1.20)$ & & & & \\
\hline Adjusted & $1.29[0.98-1.60]$ & $0.68[0.39-0.97]$ & .06 & 8.19 & .005 & 0.08 \\
\hline \multicolumn{7}{|l|}{ Reading total } \\
\hline Pre-test & $1.50(2.77)$ & $1.47(2.87)$ & & & & \\
\hline Post-test & $5.14(4.54)$ & $2.04(3.35)$ & & & & \\
\hline Adjusted & $5.12[4.23-6.02]$ & $2.05[1.21-2.90]$ & .91 & 24.47 & .000 & 0.21 \\
\hline
\end{tabular}

Note. $M=$ mean, $S D=$ standard deviation, $C I=95 \%$ confidence intervals.

Table 3 shows that children who received the songs and movement teaching had significant gains in reading compared to children in the control group, both for words included in the teaching in the songs group and for new words. The word reading by these Kindergarten children is a notable accomplishment given the relatively brief teaching intervention and the age of the children. Figure 2 below demonstrates the significant gains of reading for children in the Songs group compared to children in the control group. 


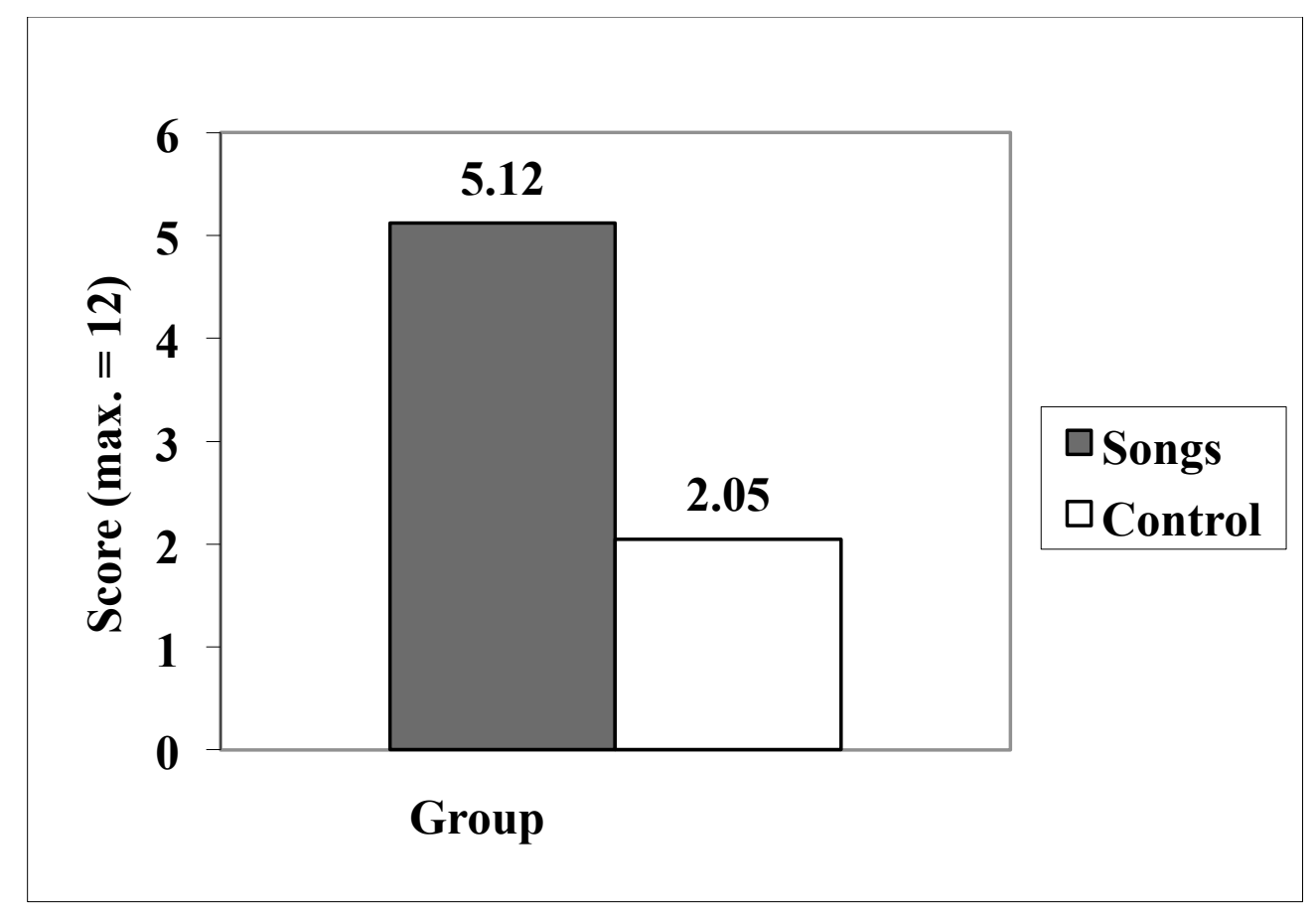

Figure 2. Treatment Effects on Reading Total Score

\section{Independent Contributions of Pre-reading Skills to Word Reading}

This research project included the assessment of key pre-reading skills, namely rhyming, letter-sounds, and phoneme identity, in addition to reading achievement. Prereading skills were assessed to allow for an examination of the potential effects of the use of songs and movement to teach these key skills, but also to examine which pre-reading skills would predict the development of word reading. A fixed-order linear regression analysis that included all of the pre-reading skills concurrently as predictors and reading achievement as the outcome variable could determine if any pre-reading skill made an independent contribution to reading after controlling for the effects of all other prereading skills. Three separate fixed-order regression analyses were conducted for the reading assessments: treatment words, new words, and total score. Only children in both the songs treatment condition were included in these analyses $(n=44)$. The results of these regression analyses are presented in Table 4 below. 
Table 4

Independent Predictions of Post-test Pre-reading Skills on Word Reading in the Treatment Group $(n=44)$

Reading word type

Treatment words

New words

\begin{tabular}{lcccccc} 
Predictor variable & \multicolumn{2}{c}{ Std. Beta } & $t$ & $p$ & Std. Beta & $t$ \\
\hline Rhyme & 0.01 & 0.13 & .895 & 0.13 & 1.36 & .182 \\
Letter-sounds & 0.24 & 2.29 & $\mathbf{. 0 2 8}$ & 0.13 & 1.15 & .258 \\
Initial phoneme & 0.26 & 2.74 & $\mathbf{. 0 0 9}$ & 0.05 & 0.50 & .621 \\
Medial phoneme & 0.63 & 3.84 & $\mathbf{. 0 0 0}$ & 0.63 & 4.24 & $\mathbf{. 0 0 0}$ \\
Final phoneme & 0.02 & 0.16 & .877 & 0.06 & 0.45 & .656 \\
& & & & & & \\
\hline
\end{tabular}

Table 4 shows that letter-sounds, initial, and medial phoneme identity were the only prereading skills to make independent contributions to reading. Surprisingly, the phonological skills of rhyming and final phoneme identity did not make independent contributions to word reading. A possible explanation of this finding is that children who could identify initial and final phonemes but not medial phonemes would make errors reading the vowel in the consonant-vowel-consonant reading test words (e.g., read bag instead of big, dig instead of $d o g$ ). The finding that rhyming did not make an independent contribution to reading, and that medial phoneme identity and letter-sounds did, suggests that children used a letter-by-letter method to read the words rather than using an orthographic analogy process based on onset-rime. More experience sounding out phonemes in medial positions might be required to effectively use a rhyming-based analogy process (e.g., learning to read cat and sat and then reading rat by analogy).

\section{Discussion}

The research reported here fills an important gap in the literature on the effects of using singing and movement to teach the key pre-reading skills of letter-sounds, phoneme skills, and rhyming, and to teach children the beginning steps of reading. Unlike previous research examining links between music and reading, this project used songs and movement to target specific pre-reading skills and word reading, and included a control group to account for the effects of language and literacy programs typically found in regular Kindergarten classrooms. The main findings of the study are that songs and 
movement are excellent methods to teach important pre-reading skills and reading to Kindergarten children, and that these experiences significantly enhance the effectiveness of the language and literacy programs typically used by Kindergarten teachers.

\section{Pre-reading Skills}

There is consistent and robust research in the field of early reading demonstrating a strong link between phonological skills, letter-sound knowledge, and reading acquisition (e.g., Adams, 1990; Kamil et al., 2000). An important finding from the research reported here is that songs and movement can be effectively used to teach lettersounds and medial phoneme skills, beyond the experience of typical literacy Kindergarten programs.

It is not surprising that children learning songs with strong rhythmic components that manipulate sounds within words would improve their ability to identify medial phonemes. However, it is surprising that the songs program did not result in increases in rhyming and initial and final phoneme identity compared to the control group. It should be noted that the teachers in the control classrooms received in-service during the previous two years of the study on teaching phoneme awareness and early reading, and that the control group children also made substantial gains in rhyming and initial and final phoneme identity.

Second, choral singing and moving to music are activities that Kindergarten children enjoy and are typically used currently in Kindergarten programs. Using songs and movement directly and systematically to teach letter-sounds and medial phoneme skills could add a focus that could enhance already strong Kindergarten programs.

\section{Word Reading}

Strong evidence was found to support the claim that learning to read can be enhanced by using songs and movement to teach children to read, especially if the first words that children learn are words they already know as lyrics in a song. This finding was notable especially in the context that the participating Kindergarten had received inservice on teaching reading and phonological skills from school district staff prior to the research project.

The first eight of the 12 test words were used in the songs program and we added the last four words to the reading test to see if the children could transfer their reading skill to new words. As well, if children demonstrated that they could read the new words, it also was evidence against the proposition that children read the songs program words using a sight word memory process. The songs program group read significantly more words than the control group and this was evidence that they were able to transfer their reading skill to read unfamiliar words. As additional evidence, several of the songs group children could be heard sounding out the words as they read.

The finding that songs and movement increased word reading significantly beyond that of the control group is important. One causal explanation is that the children in the songs program had increased letter-sound knowledge and medial phoneme identity compared to the control group, and that the treatment group children read more words 
because of the increased ability with these pre-reading skills. However, the songs and movement program also resulted in increased pre-reading skills and it is likely that the songs program also had a direct positive effect on word reading as well. What mechanisms could explain this result?

As mentioned previously, the use of songs might have facilitated long-term memory processes. For example, jingles can often be remembered after very few repetitions. Additionally, Goswami (2012) and others are finding significant relationships between perceptions of musical beat, auditory perception of rise-time tasks, and phonological and reading abilities. Most of the songs from the songs program had a pronounced beat, and the lyrics in the songs were timed to the beat, so that the prosody of lyrics in a song would coincide with the musical beat. Also, many songs segmented and blended sounds within words, and so the songs program may have facilitated the development of phonological skills within words and enhanced word reading as well. It is possible that using sand movement to teach pre-reading skills and reading was effective because it highlighted musical beat perception and the auditory perception of rise time.

\section{Pre-reading Skill Independent Contributions to Word Reading}

Fixed regressions with pre-reading skills (letter-sounds, phoneme identity) on word reading in the songs group $(n=44)$ found that letter-sounds and initial and medial phoneme identity made independent predictions on word reading. It is unclear why final phoneme identity did not make an independent contribution as well; however, once again a possible explanation is that using songs to teach reading facilitates the development of auditory perception of rise time (rise of pitch within and between syllables). Unfortunately, musical beat perception and rise time were not assessed in this project, as those findings were not published prior to completion of the current project.

\section{Choral Singing and Reading}

Children varied in the time it took to learn the songs, movements and accompanying activities. It was apparent to the participating teachers and researchers that the children enjoyed the experience of singing and movements with the group. The children who were slower to learn participated in the choral singing with the more capable children, who virtually surrounded the children with good models of performance. As the weaker children were learning the songs, they would sing the few words they knew and their lack of initial skill was not apparent to their peers. Choral singing may provide children with an enjoyable experience that facilitates scaffolding by the more capable children in a Vygotsky paradigm.

\section{Conclusion}

The findings support the view that singing can be used to directly and systematically teach key pre-reading skills and word reading. However, future research is needed to more clearly understand the cognitive and neurological mechanisms that can explain the links between singing and reading skills. Importantly, using songs to 
systematically teach pre-reading skills and word reading is potentially an important addition to already strong Kindergarten programs.

\section{References}

Adams, M. J. (1990). Beginning reading instruction in the United States. ERIC Digest.

Anvari, S. H., Trainor, Laurel. J., Woodside, J., \& Levy, B. A. (2002). Relations among musical skills, phonological processing and early reading ability in preschool children. Journal of Experimental Psychology, 83(2), 111-130.

Besson, M., Chobert, J., \& Marie, C. (2011). Transfer of training between music and speech: Common processing, attention, and memory. Frontiers in Psychology, 94(2). Doi:10.3389/fpsyg.2011.00094.

Bolduc, J. (2008). The effects of music instruction on emergent literacy capacities among preschool children: A literature review. Early Childhood Research and Practice, $10(1), 1-5$.

Bolduc, J. (2009). Effects of a music programme on kindergartners' phonological awareness skills. International Journal of Music Education, 27(1), 37-47.

Bowen, R. C. (2010). Effects of pre-kindergarten music instruction on kindergarten reading and math scores for low SES ELL students. ProQuest LLC, Ed.D. Dissertation, Trevecca Nazarene College. $91 \mathrm{pp}$.

Butzlaff, R. (2000). Can music be used to teach reading? Journal of Aesthetic Education, 34(3-4), 167-178.

Chabris, C. F. (1999). Prelude or requiem for the "Mozart Effect"? Nature, 400, 826-827.

Cooper, S. (2010). Lighting up the brain with songs and stories. General Music Today, 23(2), 24-30.

Ehri, L., Nunes, S., Stahl, S., \& Willows, D. (2001). Systematic phonics instruction helps students learn to read: Evidence from the National Reading Panel's metaanalysis. Review of Educational Research, 71(3), 393-447.

Fisher, D., \& McDonald, N. (2003). The intersection between music and early literacy instruction: Listening to literacy! Reading Improvement, 38, 106-115.

Goswami, U. (2012). Language, music, and children's brains: A rhythmic timing perspective on language and music as cognitive systems. In P. Rebuschat, M. Rohrmeier, J. A. Hawkins, \& J. Cross (Eds.), Language and music as cognitive systems (pp. 292-301). Oxford, UK: Oxford University Press.

Goswami, U., Huss, M., Mead, N., Fosker, T., \& Verney, J. P. (in press). Perception of patterns of musical beat distribution in phonological developmental dyslexia: Significant longitudinal relations with word reading and reading comprehension. Cortex.

Gromko, J. E. (2005). The effect of music instruction on phonemic awareness in beginning readers. Journal of Research in Music Education, 53(3), 199-209.

Hansen, D., Bernstorf, E., \& Stuber, G. M. (2004). The Music and literacy connection. MENC: The National Association for Music Education. 
Herrera, L., Lorenzo, O., Defior, S., Fernandez-Smith, G., \& Costa-Giomi, E. (2011). Effects of phonological and musical training on the reading readiness of nativeand foreign-Spanish-speaking children. Psychology of Music, 39(1), 68-81.

Hill-Clarke, K., \& Robinson, N. R. (2004). It's as easy as "A-B-C" and "Do-Re-Mi": Music, rhythm, and rhyme enhance children's literacy skills. Young Children, 59(5), 91-95.

Huss, M., Verney, J. P., Fosker, T., Mead, N., \& Goswami, U. (2011). Music, rhythm, rise time perception and developmental dyslexia: Perception of musical meter predicts reading and phonology. Cortex, 47(6), 674-689.

Kamil, M. L., Pearson, P. D., Moje, E. B., \& Afflerbach, P. P. (Eds.). (2011). Handbook of reading research: Vol. 4. London, UK: Erlbaum.

Kolb, G. R. (1996). Read with a beat: Developing literacy through music and song. Reading Teacher, 50, 76-77.

Lamb, S. J., \& Gregory, A. H. (1993). The relationship between music and reading in beginning readers. Educational Psychology, 13(1), 19-27.

MacLean, M., Bryant, P. E., \& Bradley, L. (1987). Rhymes, nursery rhymes and reading in early childhood. Merrill-Palmer Quarterly, 33, 255-282.

Moyeda, I. X., Gomez, I. C., \& Flores, M. T. (2006). Implementing a musical program to promote preschool children's vocabulary development. Early Childhood Research and Practice, 8(1). Retrieved from http://ecrp.uiuc.edu/v8n1/galicia.html.

Overy, K. (2003). From timing deficits to musical intervention. In G. Avanzini, Faienza, C., Minciacchi, D., Lopez, L. \& Majno, M. (Eds.). The neurosciences and music. New York, NY: New York Academy of Sciences.

Paquette, K. R., \& Rieg, S. A. (2008). Using music to support the literacy development of young English language learners. Early Childhood Education Journal, 36, 227232.

Patel, A. D. (2011). Why would musical training benefit the neural encoding of speech?; The OPERA hypothesis. Frontiers in Psychology, 2(142). doi: 10.3389/fpsyg.2011.00142

Peynircioglu, Z. F., Durgunoglu, A. Y., \& Oney-Kusefoglu, B. (2002). Phonological awareness and musical aptitude. Journal of Research in Reading, 25(1), 68-80.

Rauscher, F. H., Shaw, G. L., \& Ky, K. N. (1993). Music and spatial task performance. Nature, $365,611$.

Register, D. (2001). The effects of an early intervention music curriculum on prereading/writing. Journal of Music Therapy, 38(3), 239-248.

Routier, W. J. (2003, May). Read me a song: Teaching reading using picture book songs. Paper presented at the $48^{\text {th }}$ Annual Meeting of the International Reading Association, Orlando, Florida.

Rubinson, L. E. (2010). A correlational study of the relationships between music aptitude and phonemic awareness of kindergarten children._(Doctoral dissertation). Retrieved from ProQuest.

Standley, J. M. (2008). Does music instruction help children learn to read?: Evidence of a meta-analysis. Applications of Research in Music Education, 27(1), 17-32. 
Standley, J. M., \& Hughes, J. E. (1997). Evaluation of an early intervention music curriculum for enhancing prereading/writing skills. Music Therapy Perspectives, 15(2), 79-85.

Tendall, R. A. (2009). The effects of singing and movement in a $K-1$ reading first program. (Doctorial dissertation). Retrieved from ProQuest..

Walton, P., Canaday, M., \& Dixon, A. (2010). Using songs and movement to teach reading to Aboriginal children. Canadian Council on Learning, Vancouver, Canada. Retrieved from www.ccl-cca.ca/pdfs/FundedResearch/WaltonFinalReport.pdf.

Walton, P. D. \& Walton, L. D. (2002). Beginning reading by teaching in rime analogy: Effects on phonological skills, letter-sound knowledge, working memory, and word reading strategies. Scientific Studies of Reading, 6, 79-115.

Walton, P. D., Walton, L. D., \& Felton, K. (2001). Teaching rime analogy or letter recoding reading strategies to prereaders: Effects on prereading skills and word reading. Journal of Educational Psychology, 93, 160-180.

Walton, P. D., Bowden, M. E., Kurtz, S. \& Angus, M. (2001). Evaluation of a rime-based reading program with Shuswap and Heiltsuk First Nations prereaders. Reading and Writing, 14, 229-264.

Yopp, H. K. (1988). The validity and reliability of phonemic awareness tests. Reading Research Quarterly, 23, 159-176.

Author Biography

Dr. Patrick Walton began research in early language and literacy following 15 years of experience teaching Aboriginal children in fly-in schools in northern Saskatchewan and the Interior of BC. The primary goals of his research are to increase the success of language and literacy acquisition in young children while reflecting the culture of the child in the teaching of reading, particularly Aboriginal children. His current areas of research are studying links between songs, language and reading development, developing language curriculum in Secwepemcstin for young children, and improving the graduation rates of Aboriginal online university students. Patrick is mixed French Canadian, English and Aboriginal ancestry from Saskatchewan and Manitoba. He is an associate professor at Thompson Rivers University. 


\section{Appendix A}

Words in the Reading Assessment

\section{Treatment words}

fat

big

$\operatorname{dog}$

hat

bug

bat

sun

cat

\section{New words}

sat

hog

mug

bun 


\section{Appendix B}

Bumblebee Bill song and movement from the Songs treatment condition

Bumblebee Bill (with actions)

Oh look I see (students point above head)

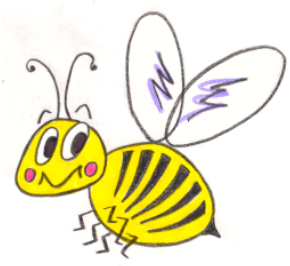

A bumblebee (make bee with raised fist, thumb \& pinky out)

Flying up high in the sky (buzz fist bee left to right above head)

Happy and free (draw smile with hand in front of face)

Buzzing near me (buzz fist bee around head)

And then he flies in my eye (point to own eye)

B - u - g, bug, bugging my toes (buzz fist bee to toes)

B - u - g, bug, right up my nose (buzz fist bee around head and point at nose)

Oh look I see (students point above heads)

A bumblebee (make bee with raised fist, thumb \& pinky out)

Flying up high in the air (buzz fist bee left to right above head)

I want to hide (arms over head, duck)

Under my bed (swoop one hand under other held flat)

Because he's buzzing my hair (buzz fist bee around hair)

B - i - t, bit, he bit my toes (make pinching motion with forefinger and thumb at toes)

B - i - t, bit, he bit my nose (make pinching motion on end of nose)

Language and Literacy

Volume 16, Issue 3, Special Issue 2014

Page 74 


\section{Bumblebee Bill}
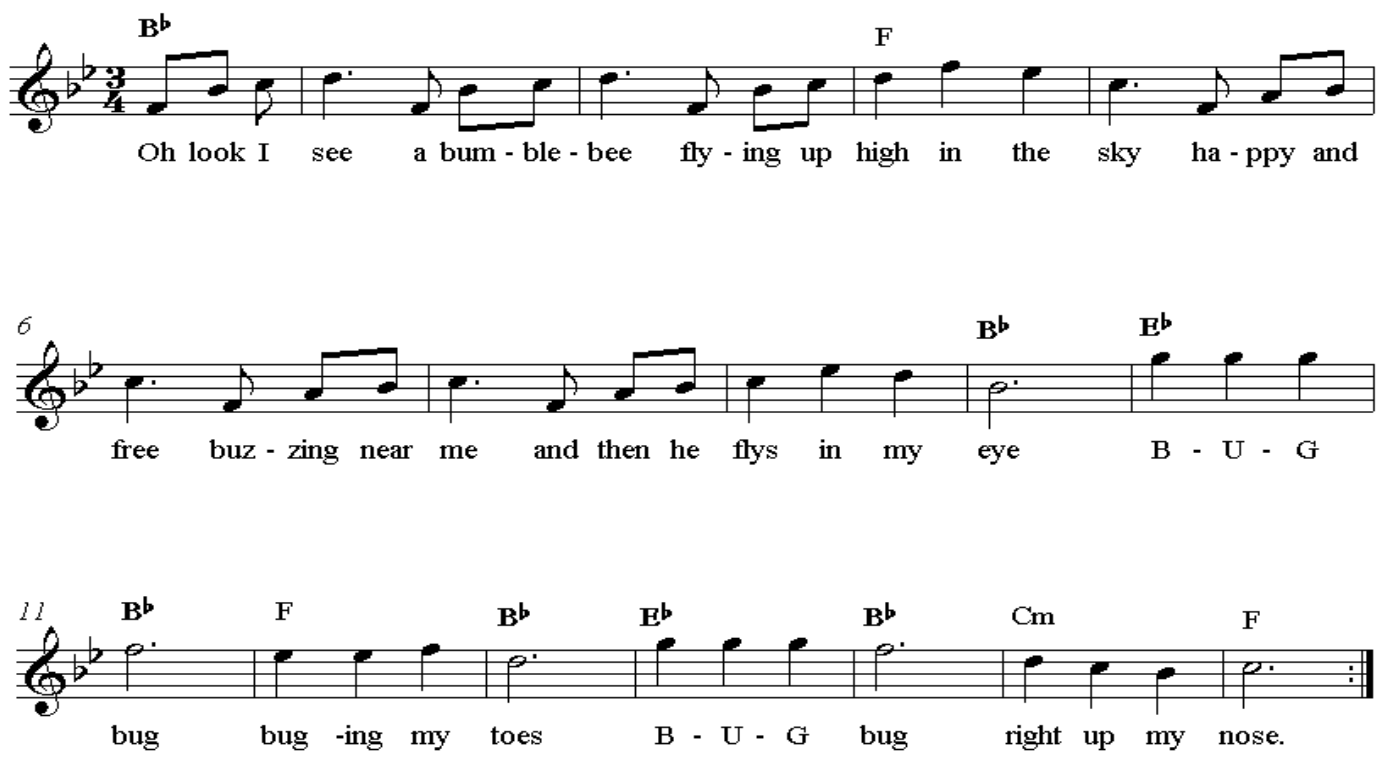

Oh look I see, a bumbleebee, flying up high in the air.

I know he dreams of flying free, and then he flies in my hair.

B-I-T BIT, he bit my toes, B-I-T BIT he bit my nose.

Oh look I see, a bumblebee, sitting on my window sill,

I know he dreams, of flying free I think that I'll call him Bill. 


\section{Appendix C}

I Am A Bug song and movement from the Songs treatment condition

I Am A Bug (with actions)

I am a bug (with actions)
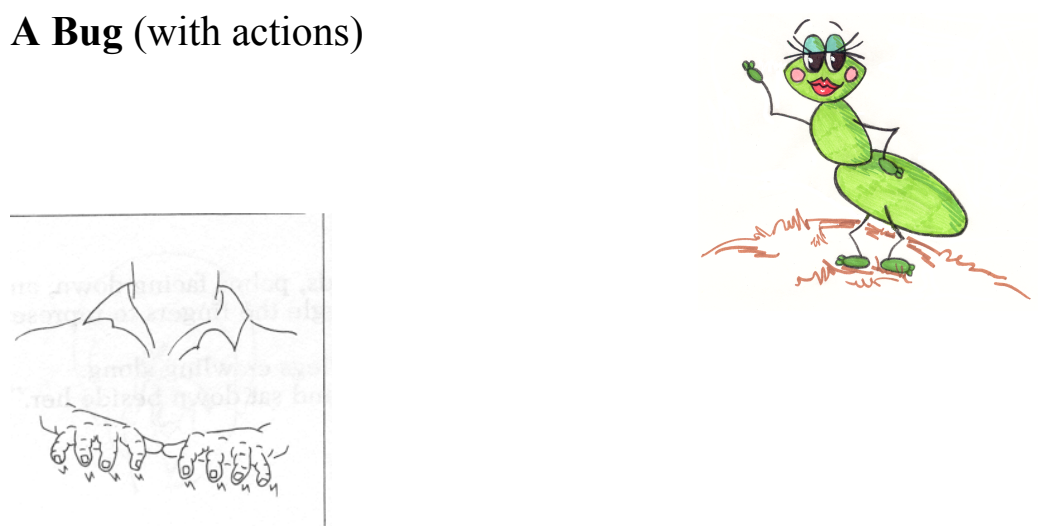

My yard is a rug (sweep right hand in front of self to show floor area)

I live on the cat

He is big and fat

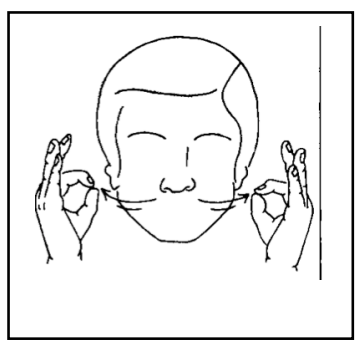

Cat runs for a jog (swing bent arms at sides as in running)

I run for the $\operatorname{dog}$ (use right hand to make a repeated scratching motion behind ear, as a dog would do)

He naps on the mat (use both index fingers to draw rectangular mat in front of body)

And back to the cat.

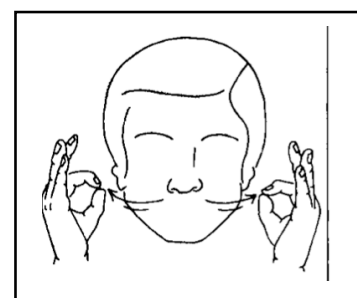

Language and Literacy $\quad$ Volume 16, Issue 3, Special Issue 2014

Page 76 


\section{I am a Bug}

C. Marshall/ M. Turner/ P. Walton
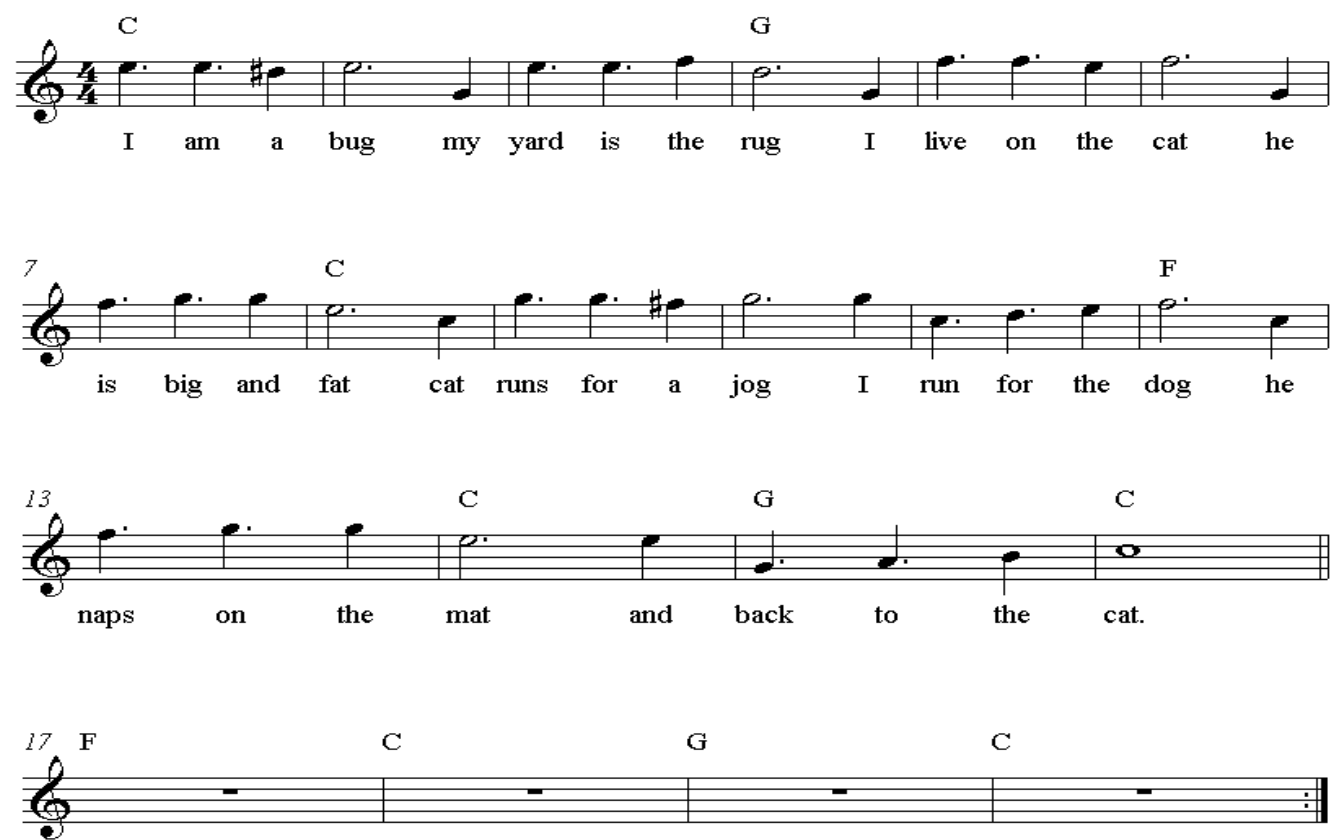